\title{
Transaction
}

\section{Evaluation of Bioactivity and Effect of Polymeric Stabilizers During Heat Treatment for the Unfolded Fraction of Human Epidermal Growth Factor}

\author{
Akon Higuchi $^{* 1,2,3}$, Jen-Hao Lee ${ }^{* 1}$, Yu Wang ${ }^{* 1}$, Wen-Yih Chen ${ }^{* 1}$, Qing-Dong Ling ${ }^{* 3,4}$, and Yung Chang ${ }^{* 5}$ \\ ${ }^{* 1}$ Department of Chemical and Materials Engineering, National Central University, No. 300, Jhongli, \\ Taoyuan 32001, Taiwan \\ *2 Department of Reproduction, National Research Institute for Child Health and Development, 2-10-1 \\ Okura, Setagaya-ku, Tokyo 157-8535, Japan \\ ${ }^{* 3}$ Cathay Medical Research Institute, Cathay General Hospital, No. 32, Ln 160, Jian-Cheng Road, Hsi-Chi \\ City, Taipei 221, Taiwan \\ ${ }^{* 4}$ Institute of Systems Biology and Bioinformatics, National Central University, No. 300, Jhongda RD., \\ Jhongli, Taoyuan 32001, Taiwan \\ ${ }^{* 5}$ Department of Chemical Engineering, R\&D Center for Membrane Technology, Chung Yuan Christian \\ University, 200, Chung-Bei Rd., Chungli, Taoyuan 320, Taiwan
}

\begin{abstract}
A method independent of the use of radioisotope monomers such as $\left[{ }^{3} \mathrm{H}\right]$-thymidine was developed to evaluate the bioactivity of human epidermal growth factor (hEGF). Briefly, DNA synthesis of fibroblasts in hEGFcontaining culture medium was evaluated via cell cycle experiments using flow cytometry; the DNA synthesis ratio was used to evaluate the bioactivity of hEGF. The unfolded fraction of hEGF, a physical parameter, was also evaluated by circular dichroism measurements. The hEGF with a higher unfolded fraction showed less bioactivity than hEGF from fibroblasts. There was a good relationship between the bioactivity of hEGF (i.e., DNA synthesis ratio) and the evaluated physical parameter of hEGF (i.e., unfolded fraction). The stability of hEGF solution containing several polymeric stabilizers during heat treatment was also determined by physical evaluation of the unfolded fraction and by bioactivity measurement of the DNA synthesis ratio. Heparin and a low molecular weight chemical of mannitol were effective stabilizers of hEGF during heat treatment.
\end{abstract}

(Received 19 November, 2010 ; Accepted 2 May, 2011)

\section{Introduction}

Application of growth factors is important in biotechnology for the manufacture of pharmaceuticals and cosmetics [1,2]. Epidermal growth factor (EGF) originating from ectodermal and mesodermal layers is a potent mitogenic factor for a variety of cultured cells [36]. In cosmetics, growth factors such as EGF are expected to participate in the generation of new skin from epidermal, epithelial and mesenchymal stem cells of the skin. However, the low stability of growth factors limits their pharmaceutical and cosmetic application. Although EGF is more biologically stable than fibroblast growth factor (FGF), lyophilized recombinant EGF (rEGF) is only stable at room temperature for 3 weeks and is recommended to be stored in desiccated form at $-18{ }^{\circ} \mathrm{C}$ [7]. Furthermore, reconstituted EGF solution should be stored at $4{ }^{\circ} \mathrm{C}$ for immediate use (between 2-7 days), and at less than $-18{ }^{\circ} \mathrm{C}$ for future use [7].

Several reports have described the enhancement of the biological stability of FGF [8-13]. Zakrzewska et al. developed multiple mutants of FGF-1 with a highly stable conformation; the mutants showed denaturation temperatures up to 27 degrees higher than that of wildtype FGF-1, and all mutants were biologically competent in several biological assays [8]. On the other hand, Kamal et al. demonstrated that the covalent linkage of FGF-2 to nanofibrillar surfaces composed of a network of polyamide nanofibers resulted in the maintenance of biological efficacy when stored dry for 6 months at $25^{\circ} \mathrm{C}$ or at $4{ }^{\circ} \mathrm{C}[9]$.

Compared to the research carried out on FGF to maintain its biological activity, only a few studies have been reported on the stabilization of EGF [14-18].

Finkenaur reported that EGF in solution could be stabilized by the addition of water-soluble cellulose, based on receptor binding assays of EGF to epidermal carcinoma cells [14]. However, a detailed evaluation of the biological activity of EGF was not reported. Yang et al. found that a carboxylvinyl polymer stabilized EGF in 


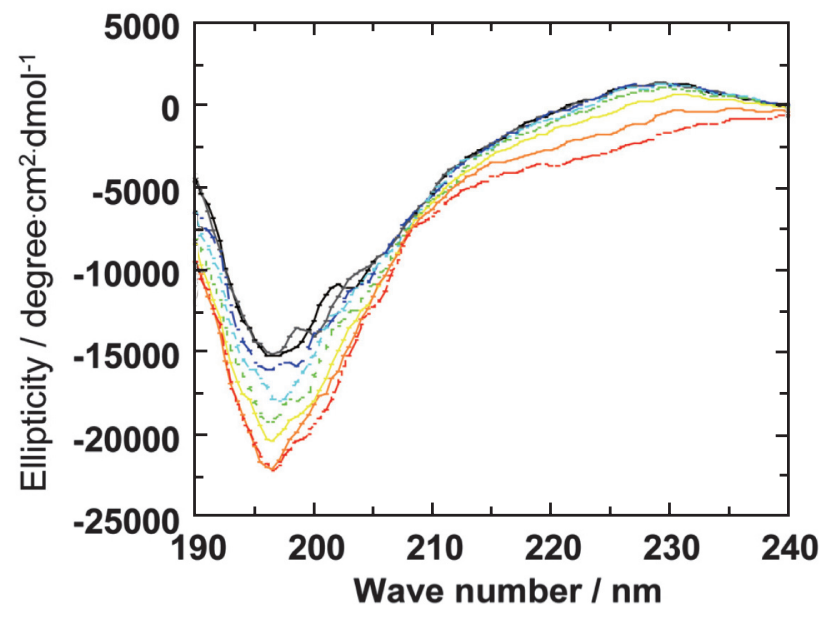

Fig. $1 \mathrm{CD}$ spectra of heat-treated hEGF solution $(0.05 \mathrm{mg} / \mathrm{mL}, \mathrm{pH} 7.4)$ at $25,30,40,50,60,70$, 80 and $90{ }^{\circ} \mathrm{C}$ (from top to bottom) at $225 \mathrm{~nm}$.

solution via quantification of EGF using enzyme-linked sorbed assay (ELISA) [15]. The quantification of EGF by ELISA is simple and results in stable data, while measurements of the biological activity of EGF are more time-consuming and costly. Again, the biological activity of EGF was not reported. Because no relationship has been reported between the amount of EGF measured by ELISA and the biological activity of EGF, it may be difficult to rely on the previous results. A simple and standardized assay of the biological activity of EGF has not yet been reported from physical measurements. In this study, we investigated the conformational change of human EGF (hEGF) using circular dichroism (CD) as well as the biological activity of EGF using DNA synthesis of fibroblasts; we evaluated EGF treated with heat at several temperatures. The goal of this research was to determine the relationship between physical parameters of EGF (i.e., unfolded fraction determined by $\mathrm{CD}$ measurements) and its bioactivity (i.e., DNA synthesis ratio of human fibroblasts determined from cell cycle measurements). We also report an optimal thermal stabilizer for EGF from both perspectives.

\section{Experimental}

\subsection{Materials}

hEGF was purchased from Prospec-Tany Technogene Ltd. Human foreskin fibroblast cells (Hs68, BCRC60038 [ATCC CRL-1635]) were obtained from the Bioresource Collection and Research Center (BCRC, Food Industry Research and Development Institute). Poly (acrylic acid) (PAA, 306231-100G, Sigma-Aldrich, Inc.), poly(methacrylic acid) (PMMA, 00578, Polysciences, Inc.), polyvinyl alcohol (PVA, 2117819, Kokusan
Chemical Co., Ltd), heparin sodium salt (Heparin, $\mathrm{H}$ 4784-250MG, Sigma-Aldrich Inc.), and D-mannitol (Mannitol, M4125-100G, Sigma-Aldrich, Inc.) were used as received. Propidium iodide (PI, R4170-10MG, SigmaAldrich, Inc.), ribonuclease A from bovine pancreas (RNAse, R6513-500MG, Sigma-Aldrich, Inc.) and Triton X-100 (M236-10ML-5PK, Amresco., Inc.) were used as received. Other chemicals were of reagent grade and were used without further purification. Ultrapure water was used in all experiments.

\subsection{Determination of unfolded fraction of hEGF from circular dichroism measurements \\ hEGF in phosphate buffer solution $(0.05 \mathrm{mg} / \mathrm{ml}, \mathrm{pH}$} 7.4) either containing or not containing polymeric stabilizer ( 0 or $0.05 \mathrm{wt} \%$ ) was heat-treated at between 25 and $90{ }^{\circ} \mathrm{C}$ (at 25, 30, 40, 50, 60, 70, 80, and $90{ }^{\circ} \mathrm{C}$ respectively) for $10 \mathrm{~min}$. PAA, PMMA, PVA, heparin, and mannitol were selected as hEGF stabilizer candidates. Circular dichroism (CD) of the hEGF solution was measured using a circular dichroism spectrophotometer (J-810, Jasco Corporation). The unfolded fraction of the heat-treated hEGF solution was evaluated from the equation below, as reported by Leslie et al. : [19]

$$
\text { Unfolded fraction }=\left(\theta_{\mathrm{F}}-\theta_{\mathrm{obs}}\right) /\left(\theta_{\mathrm{F}}-\theta_{\mathrm{U}}\right)
$$

where $\theta_{\mathrm{F}}$ was the mean residue molar ellipticity at $232 \mathrm{~nm}$ for the folded state of hEGF, which was defined as the mean residue molar ellipticity of hEGF at $25{ }^{\circ} \mathrm{C}(1223.3$ degree $\left.\mathrm{cm}^{2} / \mathrm{dmol}\right) ; \theta_{\mathrm{U}}$ was the mean residue molar ellipticity at $232 \mathrm{~nm}$ for the unfolded state of hEGF, which was defined as the mean residue molar ellipticity of $\mathrm{hEGF}$ at $90{ }^{\circ} \mathrm{C}$ (i.e., -1208.1 degree $\mathrm{cm}^{2} / \mathrm{dmol}$ ); $\theta_{\text {obs }}$ was the mean residue molar ellipticity of hEGF in the sample solution.[19]

\subsection{Bioactivity analysis of hEGF using cell cycle measurements}

Human foreskin fibroblasts (Hs68) were maintained in DMEM supplemented with $25 \mathrm{mg} / \mathrm{l}$ of streptomycin sulfate, $3.5 \mathrm{mg} / \mathrm{l}$ benzylpenicillin potassium and $10 \%$ fetal bovine serum (FBS, JRH Bioscience, Lenexa, KS) in a $5 \% \mathrm{CO}_{2}$ atmosphere at $37{ }^{\circ} \mathrm{C}$ [20-22]. In this study, Hs68 cells at passage number of 19 were used. The culture medium containing 10\% FBS was exchanged for one containing $1 \% \mathrm{FBS}$, and the cells were cultured for $12 \mathrm{~h}$. Subsequently, hEGF was added to the culture medium. Next, hEGF solutions, with or without the stabilizers PAA, PMMA, PVA, heparin and mannitol, were heattreated at $25-90{ }^{\circ} \mathrm{C}$ for $10 \mathrm{~min}$. The cells were incubated for $24 \mathrm{~h}$ in a $5 \% \mathrm{CO}_{2}$ atmosphere at $37^{\circ} \mathrm{C}$. The cell cycle 

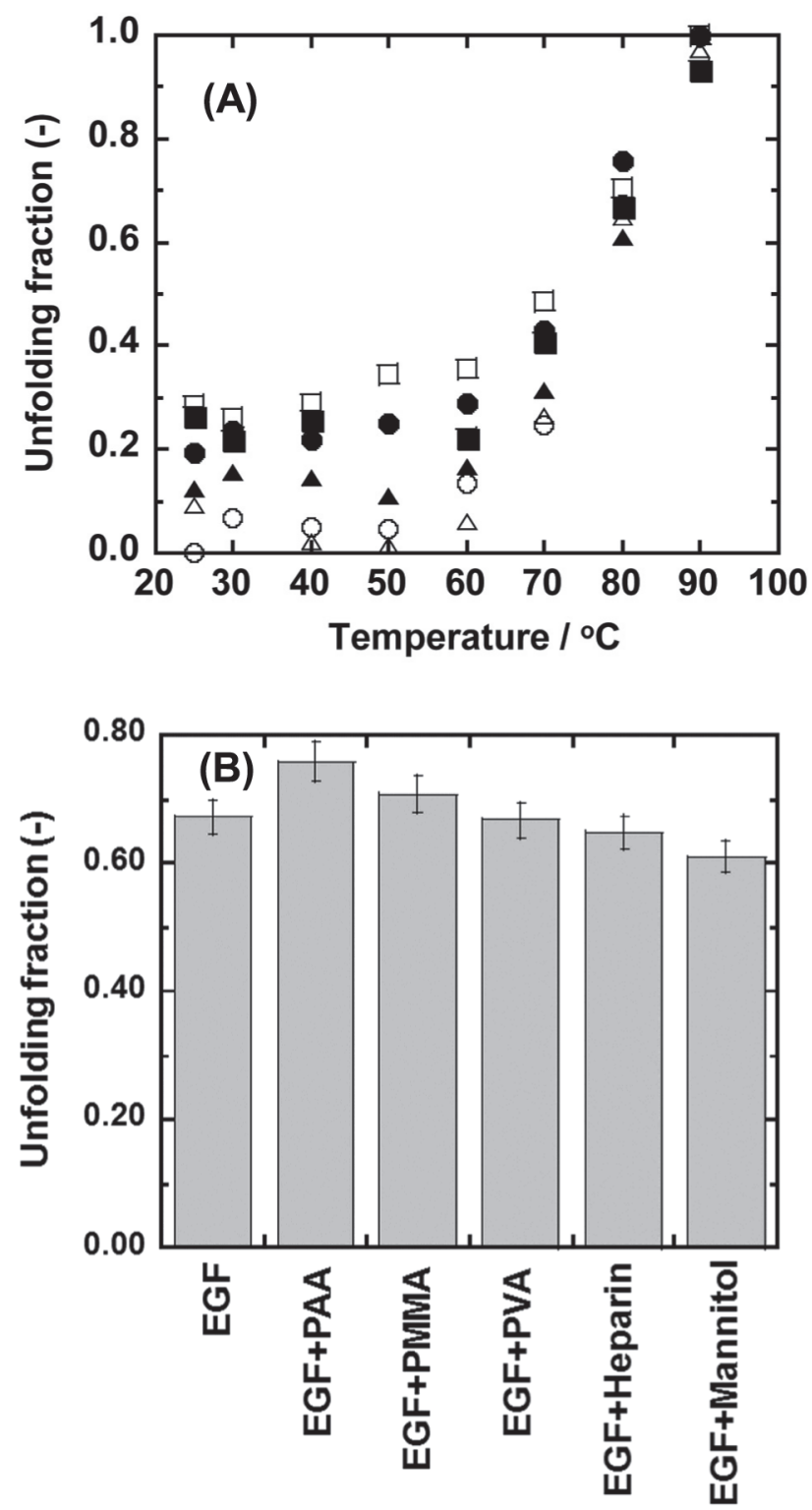

Fig. 2 Unfolded fraction of hEGF. (A) Dependence of the content of the unfolded fraction of hEGF in solutions $(0.05 \mathrm{mg} / \mathrm{mL}, \mathrm{pH} 7.4)$ containing one of the specific polymeric stabilizers $[0.05 \mathrm{wt} \%$

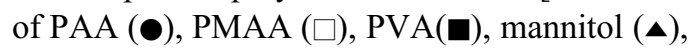
and heparin $(\Delta)]$ or not containing polymeric stabilizers $(\bigcirc)$ on the heat-treated temperature. (B) Unfolded fraction of the hEGF solution (0.05 mg/mL, $\mathrm{pH} 7.4)$ containing one of the specific polymeric stabilizers $(0.05 \mathrm{wt} \%$ of PAA, PMAA, PVA, heparin and mannitol) or not containing polymeric stabilizers at the heat treatment temperature of $80^{\circ} \mathrm{C}$. The data are expressed as the means SD of four independent measurements.

of the fibroblasts was analyzed using the following procedures.

Hs68 cells were trypsinized and resuspended in phosphate-buffered saline (PBS, pH7.4). Next, they were fixed with $70 \%$ ethanol and kept at $-20{ }^{\circ} \mathrm{C}$ overnight. The cell pellets were treated with PI/Triton X-100 solution (20 $\mu \mathrm{g} / \mathrm{mL}$ PI, $0.1 \%$ Triton X-100 and $0.2 \mathrm{mg} / \mathrm{mL}$ RNAse) for $30 \mathrm{~min}$, and were subjected to flow cytometry measurements. A single-parameter histogram of DNA allowed the discrimination of cell populations existing in the $\mathrm{G}_{\mathrm{o}} / \mathrm{G}_{1}$ (2N DNA content), $\mathrm{S}$ (between $2 \mathrm{~N}$ and $4 \mathrm{~N}$ ) and $\mathrm{G}_{2} / \mathrm{M}(4 \mathrm{~N})$ phases of the cell cycle ; $\mathrm{N}$ was the number of chromosomes [23]. Percentage of each phase was calculated based on the numbers of gated cells displaying fluorescence intensity of PI correlating to the cell cycle stages. The ratio of the cells performing DNA synthesis to the total number of cells (i.e., DNA synthesis ratio) was defined by the equation below :

$$
\begin{array}{r}
\text { DNA synthesis ratio }(\%)=\text { Cell ratio of S phase }(\%)+ \\
\text { Cell ratio of } \mathrm{G}_{2} / \mathrm{M} \text { phase }(\%)
\end{array}
$$

\section{Results and discussion}

\subsection{Unfolding fraction of heat-treated hEGF}

The conformational change of hEGF due to the heat treatment of hEGF and unfolding fraction of heat-treated hEGF were investigated to develop the relationship between physical evaluation of hEGF activity (i.e., unfolding fraction of EGF by $\mathrm{CD}$ measurements) and bioactivity of EGF (i.e., DNA synthesis ratio of human fibroblasts from cell cycle measurements). hEGF without addition of polymeric stabilizer in phosphate buffer solution (PBS) was heated from 25, 30, 40, 50, 60, 70, 80 and $90{ }^{\circ} \mathrm{C}$ for $10 \mathrm{~min}$, and subsequently $\mathrm{CD}$ spectra of hEGF solution was measured using CD spectrophotometer. Fig. 1 shows the CD spectra of heattreated hEGF solution at each temperature. The secondary structure of hEGF was mainly random coil, because the negative signal at $197 \mathrm{~nm}$ was extensively observed, and almost no negative peaks were found at $208 \mathrm{~nm}$ and 222 $\mathrm{nm}$ that were specifically observed in $\alpha$-helix conformation [24]. The isodichronic point of hEGF was found as a function of heat-treated temperature at 208 and $240 \mathrm{~nm}$, and thus indicated that the conforma- tion of hEGF was changed from one state to another state, i.e., folding state to unfolding state as a function of heattreated temperature. The unfolding fraction of heattreated hEGF was evaluated from the method of Leslie et al. [19] using eq. (1), and dependence of unfolding fraction of hEGF on heat-treated temperature of hEGF without addition of stabilizers is shown in Fig. 2(A). It was found that the unfolding fraction of hEGF increased with the increase of the heat-treated temperature of hEGF. 
(a) $10 \%$ FBS

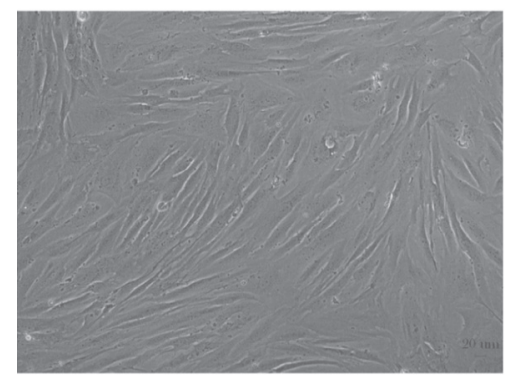

(d) $2 \mathrm{ng} / \mathrm{mL} \mathrm{hEGF}$

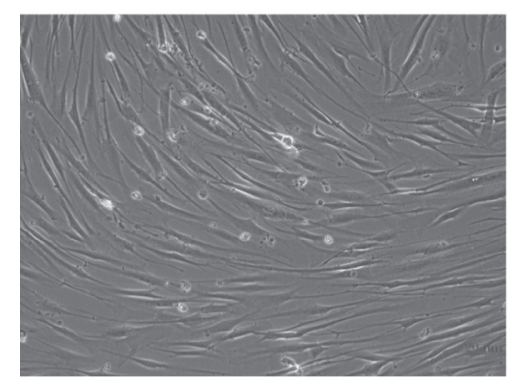

(b) Serum-free

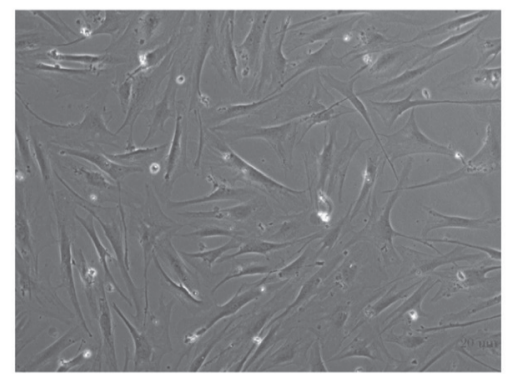

(e) $1 \mathrm{ng} / \mathrm{mL} \mathrm{hEGF}$

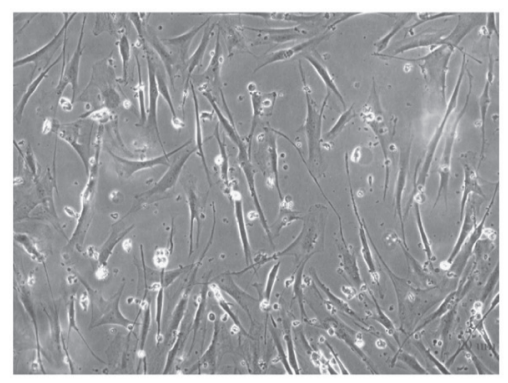

(c) $10 \mathrm{ng} / \mathrm{mL}$ hEGF

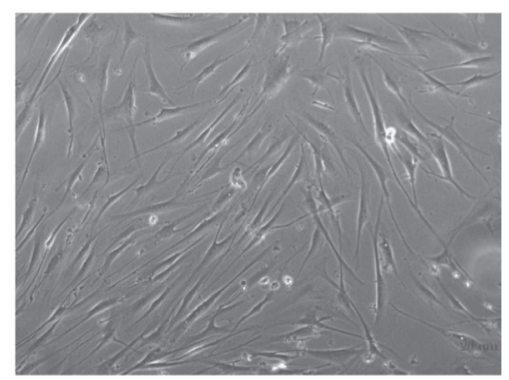

(f) $0.2 \mathrm{ng} / \mathrm{mL}$ hEGF



Fig. 3 Micrographs of Hs68 cells cultured in media containing 10\% FBS (a), serum-free medium (b), $10 \mathrm{ng} /$ $\mathrm{mL} \mathrm{hEGF} \mathrm{(c),} 2 \mathrm{ng} / \mathrm{mL} \mathrm{hEGF}, 1 \mathrm{ng} / \mathrm{mL} \mathrm{hEGF}$ and $0.2 \mathrm{ng} / \mathrm{mL}$ hEGF.

\subsection{Unfolding fraction of heat-treated hEGF in the existence of polymeric stabilizer}

Unfolding fraction of hEGF solution containing one of stabilizers $(0.05 \mathrm{wt} \%$ of PAA, PMA, PVA, mannitol and heparin) was also analyzed from eq. (1) as a function of temperature to evaluate the most efficient polymeric stabilizer to generate higher thermal stability to hEGF. Fig. 2(A) also shows dependence of unfolding fraction of hEGF solution containing one of the specific polymeric stabilizers on heat-treated temperature of hEGF. If the unfolding fraction of hEGF containing the stabilizer was less than that of hEGF containing no stabilizer, the stabilizer was effectively considered to stabilize the conformation of hEGF, which may lead to maintain the bioactivity of hEGF at longer storage time and/or have higher thermal stability by the addition of adequate stabilizer into hEGF solution. To analyze the stabilizing effect of the polymeric stabilizers quantitatively, the unfolding fraction of hEGF solution containing and not containing stabilizers at $80^{\circ} \mathrm{C}$ of heat-treated temperature of hEGF was plotted in Fig. 2(B), because that at $70{ }^{\circ} \mathrm{C}$ is not so significantly different from that at $25-60^{\circ} \mathrm{C}$ and that at $90^{\circ} \mathrm{C}$ is nearly the same fraction around 1.0 in any cases. Heparin and mannitol are the candidates of the adequate stabilizer of hEGF from Fig. 2(B), because the unfolding fraction of hEGF solution containing heparin or mannitol shows less unfolding fraction than that without containing the stabilizers. Mannitol was found to be the most appropriate stabilizer of hEGF from CD measurements in this case.

\subsection{Bioactivity of hEGF}

Bioactivity of hEGF was typically measured by $\left[{ }^{3} \mathrm{H}\right]-$ thymidine incorporation experiments (i.e., DNA synthesis) as reported in the literature [25]. The method has been widely used to evaluate bioactivity of growth factor such as EGF and FGF, and the method was cited extensively on several articles [9,25-27]. However, this method needs to use radioactive monomers of $\left[{ }^{3} \mathrm{H}\right]$ thymidine, and therefore, the special facility and techniques are necessary to treat the radioactive monomers that might generate tumor or cacogenesis in animals. Therefore, the evaluation method of bioactivity of hEGF was developed in this study where DNA synthesis of fibroblasts in the culture medium containing hEGF was evaluated from cell cycle experiments using flow cytometry. Several concentration of hEGF (i.e., 0-15 $\mathrm{ng} / \mathrm{mL}$ ) was added into the culture medium, and fibroblasts were incubated in the culture medium for one day (Fig. 3). Subsequently cell cycle of fibroblasts was investigated using flow cytometry for bioactivity evaluation of hEGF (see Fig. 4(A)). The DNA synthesis ratio (\%) of fibroblasts with and without hEGF were evaluated by eq. (2), and was shown in Fig. 4(B). DNA synthesis ratio increased with increase of hEGF concentration until $5 \mathrm{ng} / \mathrm{mL}$ of hEGF and shows constant at $\mathrm{hEGF}$ concentration $>5 \mathrm{ng} / \mathrm{mL}$. It is found that DNA 



Fig. 4 Bioactivity of hEGF measured from cell cycle experiments of Hs68 cells using flow cytometry. (A) Histogram showing cell cycle distribution of Hs68 cells cultured in medium containing $5 \mathrm{ng} /$ $\mathrm{mL}$ of hEGF. (B) Dependence of the DNA synthesis ratio of Hs68 cells on the concentration of hEGF in the culture medium. The data are expressed as the means SD of four independent measurements.

synthesis ratio can demonstrate the bioactivity of hEGF using the cell cycle experiments using flow cytometry without usage of radioisotope monomer such as $\left[{ }^{3} \mathrm{H}\right]-$ thymidine.

\subsection{Relationship between bioactivity and unfolding fraction of $\mathrm{hEGF}$}

Bioactivity (i.e., DNA synthesis ratio) of heat-treated hEGF without polymeric stabilizers was investigated from cell cycle experiments of Hs68 cells using flow cytometry where hEGF was heat-treated at $25-90{ }^{\circ} \mathrm{C}$ for 10 min, and was shown in Fig. 5(A). It was found that the DNA synthesis ratio decreased with the increase of heattreated temperature of hEGF. Relationship between bioactivity of heat-treated hEGF (i.e., DNA synthesis ratio) and unfolding fraction of heat-treated hEGF was also investigated, and is shown in Fig. 5(B). The amount of DNA synthesis ratio decreased with the increase of unfolding fraction of hEGF. These results indicates that hEGF having higher unfolding fraction has less bioactivity of hEGF to fibroblasts, which demonstrated that there is a good relationship between bioactivity of hEGF (i.e., DNA synthesis ratio) and physical parameter of hEGF (i.e., unfolding fraction). Therefore, these results generate the idea that it might be possible to estimate the bioactibity of hEGF from the physical parameter of unfolding fraction of hEGF measured by $\mathrm{CD}$ spectroscopy.

Bioactivity of heat-treated hEGF (i.e., DNA synthesis ratio) in culture medium containing polymeric stabilizers was investigated from cell cycle experiments using flow cytometry where hEGF solution containing single stabilizers was heat-treated at $80{ }^{\circ} \mathrm{C}$ for $10 \mathrm{~min}$. Fig. 6 summarizes the relationship between unfolding fraction of hEGF and DNA synthesis ratio of fibroblasts cultured in the medium containing heat-treated hEGF with polymeric stabilizers. It is found that DNA synthesis ratio of fibroblasts containing heat-treated hEGF decrease with the increase of unfolding fraction of hEGF. This indicates that hEGF having higher unfolding fraction has less bioactivity of hEGF to fibroblasts.

\section{Conclusion}

The DNA synthesis ratio was successively obtained from cell cycle measurements to evaluate the bioactivity of hEGF without using radioisotope monomers such as $\left[{ }^{3} \mathrm{H}\right]$-thymidine ; in contrast, DNA synthesis of fibroblasts in culture medium containing hEGF was evaluated via cell cycle experiments using flow cytometry. The physical parameter, unfolded fraction of hEGF, was evaluated from circular dichroism measurements. There was a good correlation between bioactivity of hEGF (i.e., DNA synthesis ratio) and the physical parameter of hEGF (i.e., unfolded fraction). The stabilization of hEGF solution by several polymeric stabilizers during heat treatment was also evaluated from the unfolded fraction of hEGF and bioactivity as determined by the DNA synthesis ratio. Heparin and a low molecular weight chemical of mannitol effectively stabilized hEGF during heat treatment based on both bioactivity measurement of DNA synthesis ratio and physical measurement of the unfolded fraction of hEGF. Mannitol is used as a stabilizer of several proteins. For example, mannitol can stabilize conformation and biological activity of lysozyme [28]. This is originated by polyol characteristics of 

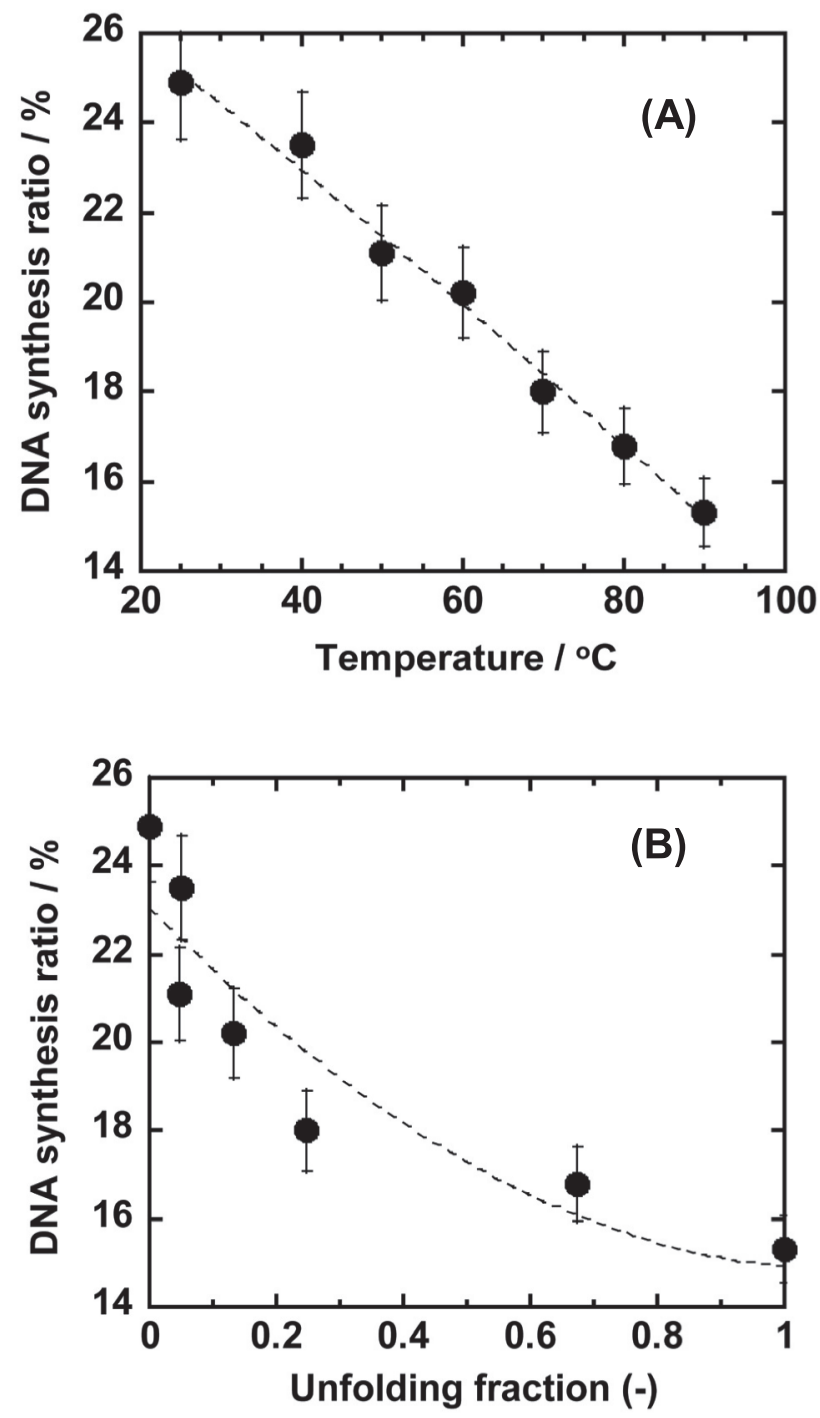

Fig. 5 DNA synthesis ratio of Hs68 cells cultured in medium containing $50 \mathrm{ng} / \mathrm{mL}$ of heat-treated hEGF. (A) Dependence of the DNA synthesis ratio of Hs68 cells cultured in media containing heat-treated hEGF without polymeric stabilizers on the heat-treated temperature of hEGF. (B) Relationship between the unfolded fraction of heat-treated hEGF and the DNA synthesis ratio of Hs68 cells cultured in medium containing heat-treated hEGF without polymeric stabilizers. The data are expressed as the means \pm SD of four independent measurements.

mannitol, which protects aggregation, deamidation, and oxidation. Heparin is categorized as a glycosaminoglycan, which contains many hydroxyl group (polyols) in its molecule. The hydroxyl group in heparin molecule should be contributing to the stabilization of hEGF in this study. There might have a possibility that there is an optimal molecular weight and molecular weight distribution of heparin contributing to the stabilization of hEGF.

Physical parameter analysis (i.e., unfolded fraction measurements) of growth factors such as EGF should be



Fig. 6 Relationship between the unfolded fraction of the heat-treated hEGF and the DNA synthesis ratio of fibroblasts cultured in medium containing $50 \mathrm{ng} / \mathrm{mL}$ of heat-treated hEGF with $0.05 \mathrm{wt} \%$ of several polymeric stabilizers. The data are expressed as the means $\pm \mathrm{SD}$ of four independent measurements.

effective as a first screening assay to find optimal stabilizers for maintenance of bioactivity of growth factors in solution or thermal stability at high temperature because this method does not require radioisotope monomers or special facilities. Furthermore, a great amount of stable data can be quickly obtained using the physical evaluation method compared to biological experiments (i.e., DNA synthesis ratio).

\section{Acknowledgement}

This research was partially supported by the National Science Council of Taiwan under Grants NSC 97-2221-E-008-011-MY3, NSC97-2120-M-008-002 and NSC98-2120-M-008-002. This work was also financed by the VGHUST Joint Research Program, the Tsou's Foundation (VGHUST97-P3-08 and VGHUST98-P3-11) and a Cathay General Hospital Project (98CGH-NCU-B1, 99CGH-NCU-B2). We also acknowledge Grants-in-Aid for the Scientific Research Grant (No. 21500436) from the Ministry of Education, Culture, Sports, Science and Technology of Japan.

\section{References}

1. D. G. Kim, M. K. Min, S. C. Ahn, J. K. Kim, and I. S. Kong, Biotechnol. Lett., 31, 259 (2009).

2. M. Manela-Azulay, and E. Bagatin, Clinics in Dermatology, 27, 469 (2009). 
3. T. Mitsudomi, and Y. Yatabe, FEBS J., 277, 301 (2010).

4. Y. Takahashi, T. Miyamoto, H. Shiku, R. Asano, T. Yasukawa, I. Kumagai, and T. Matsue, Anal. Chem., 81, 2785 (2009).

5. H. Ogiso, and R. Taguchi, Anal. Chem., 80, 9226 (2008).

6. Y. Fang, A. M. Ferrie, N. H. Fontaine, and P. K. Yuan, Anal. Chem., 77, 5720 (2005).

7. http : //www.prospecbio.com/EGF_Human_2_12/

8. M. Zakrzewska, D. Krowarsch, A. Wiedlocha, S. Olsnes, and J. Otlewski, J. Mol. Bio., 352, 860 (2005).

9. A. Nur-E-Kamal, I. Ahmed, J. Kamal, A. N. Babu, M. Schindler, and S. Meiners, Mol. Cell Biochem., 309, 157-166 (2008).

10. K. Motomura, A. Hagiwara, A. Komi-Kuramochi, Y. Hanyu, E. Honda, M. Suzuki, M. Kimura, J. Oki, M. Asada, N. Sakaguchi, F. Nakayama, M. Akashi, and T. Imamura, Biochim. Biophys. Acta, 1780, 1432 (2008).

11. S. Friedman, X. Zhan, and T. Maciag, Biochem. Biophys. Res. Comm., 198, 1203-1208 (1994).

12. A. Szlachcic, M. Zakrzewska, D. Krowarsch, V. Os, R. Helland, A. O. Smalås, and J. Otlewski, Acta Cryst., D65, 67-73 (2009).

13. M. Zakrzewska, A. Wiedlocha, A. Szlachcic, D. Krowarsch, J. Otlewski, and S. Olsnes, J. Biol. Chem. 284, 25388-25403 (2009).

14. A. L. Finkenaur, US Patent, 4,717,717 (1988).
15. Z. Yang, and Z. Lee, Japanese Published Patent Application, JP-2003-523399 (2003).

16. B. Y. Lu, C. T. Jiang, and J. Y. Chang, Biochemistry, 44, 15032 (2005).

17. C. H. Yang, Y. B. Huang, P. C. Wu, and Y. H. Tsai, Process Biochem., 40, 1661 (2005).

18. J. X. Song, P. Xu, A. Koutychenko, and F. Ni, Biopolymers, 65, 373 (2002).

19. A. Leslie, C. Holladay, R. Savage, S. Cohen, and D. Puett, Biochemistry, 15, 2624 (1976).

20. C. Amatore, S. Arbault, and M. Erard, Anal. Chem., 80, 9635 (2008).

21. A. Higuchi, and Y. Tsukamoto, J. Biomed. Mater. Res., 71A, 470 (2004).

22. A. Higuchi, Y. Takanashi, N. Tsuzuki, T. Asakura, C.-S. Cho, T. Akaike, and M. Hara, J. Biomed. Mater. Res., 65A, 369 (2003).

23. G. Sitton, F. Srienc, Cytometry, 73A, 538 (2008).

24. J. T. Yang, C. S. Wu, and H. M. Martinez, Methods Enzymol., 130, 208 (1986).

25. J. H. Park, M. Y. Lee, J. S. Heo, and H. Han, J. Cell Prolif., 41, 786 (2008).

26. M. Zakrzewska, D. Krowarsch, A. Wiedlocha, and J. Otlewski, Design \& Selection, 17, 603 (2004).

27. D. P. Calnan, A. Fagbemi, J. Berlanga-Acosta, T. Marchbank, T. Sizer, K. Lakhoo, A. D. Edwards, and R. Playford, J. Gut., 47, 622 (2000).

28. S. Singh and J. Singh, AAPS PharmSciTech., 4, E42 (2003). 